\title{
A fotografia na era da incompetência técnica
}

\section{The photography in the age of technical incompetence}

\author{
Maria Luisa Hoffmann \\ Jornalista e mestre em Comunicação pela Universidade Estadual de Londrina (UEL). Doutora em Ciências da Comunicação \\ pela Universidade de São Paulo (USP). Professora convidada da Especialização em Fotografia: Práxis e Discurso Fotográfico da \\ Universidade Estadual de Londrina (UEL). Docente na Graduação em Comunicação Social da Universidade do Oeste Paulista \\ (Unoeste). \\ <maluhoffmann@yahoo.com>
}

\section{Michel de Oliveira}

Mestrando em Comunicação e especialista em Fotografia: Práxis e Discurso, ambos pela Universidade Estadual de Londrina (UEL). Graduado em Comunicação Social - Jornalismo, pela Universidade Federal de Sergipe (UFS).

<michel.os@hotmail.com.br>

\section{RESUMO}

Este artigo parte do controverso "selfie do macaco" para levantar uma questão: quem fotografa hoje, o homem ou a câmera? Em busca de traçar uma resposta possível, apresenta um breve histórico do processo de automação do ato fotográfico e um esboço críticoanalítico nominado de incompetência técnica, com o objetivo de compreender como a programação da câmera se sobrepôs à vontade de quem a usa. A discussão tem como aporte principal a Teoria Crítica de Benjamin e Flusser, e as contribuições de Soulages e Rouillé. A partir desse exercício teórico-conceitual, foi possível apreender que a intenção humana tem sido substituída pelas predefinições dos aparelhos, um dos motivos pelo qual a fotografia ainda é vista como uma construção meramente técnica, afetada em seu potencial comunicativo.

Palavras-chave: Fotografia. Cultura visual. Automação do ato fotográfico.

\begin{abstract}
This article focuses on the controversial "monkey selfie" to raise a question: who shoots pictures today, the man or the camera? Seeking to attain a possible answer, it presents a brief history of the automation process in the photographic act and a critical-analytical outline titled technical incompetence, in order to understand how the camera automatic modes surpassed the will of the snapper. This discussion has as its main influences the Critical Theory of Benjamin and Flusser, and the contributions of Soulages and Rouillé. From this theoretical-conceptual exercise, it was possible to apprehend that the human intention has been replaced by the devices' default settings, one of the reasons why photography is still seen as a purely technical construction, affected in its communicative potential.
\end{abstract}

Keywords: Photography. Visual culture. Automation of the photographic act. 
"Quando todos, enfim, têm uma câmera na mão ou no bolso, é preciso que alguém tenha uma ideia na cabeça".

Juremir Machado

\section{O deboche dos macacos}

O fotógrafo de natureza, David Slater, não imaginou que sua expedição à Indonésia para registrar os hábitos dos macacos-preto-de-crista, em 2011, renderia uma fotografia bastante controversa. Em uma das saídas à floresta da ilha Sulawesi, Slater foi surpreendido em um momento de distração: um dos macacos conseguiu tirar a câmera do tripé e a levou para o bando.

O equipamento passou pelas mãos dos atrevidos primatas, que dispararam o obturador várias vezes. Quando o fotógrafo conseguiu recuperar a câmera, viu que entre as inúmeras fotografias desfocadas ou mal enquadradas, havia registros bastante nítidos e com enquadramento satisfatório, incluindo alguns "autorretratos" curiosos, nos quais os macacos reagiam ao reflexo na lente da câmera com expressões engraçadas para os padrões humanos.

As melhores fotografias da expedição foram publicadas no site de Slater e na agência Caters. A história foi noticiada por alguns jornais de destaque, a exemplo britânico do The Guardian. Mas foi somente três anos depois, em 2014, que o caso ganhou notoriedade internacional, quando Slater pediu que uma das fotografias fosse retirada da Wikimedia Commons, biblioteca de compartilhamento de arquivos livres de direitos autorais da Wikipedia.com.

O "selfie do macaco", como ficou conhecida a fotografia (Figura 01), tornouse alvo de disputa judicial. O fotógrafo alegou que a Wikipedia se apropriou indevidamente da imagem. Os representantes da enciclopédia virtual, por sua vez, defendiam que o registro era do primata, portanto, Slater não era detentor dos direitos legais.

De acordo com parecer do US Copyright Office, órgão regulador de direitos autorais dos Estados Unidos, a fotografia era, sim, obra do macaco. Como pelas leis estadunidenses esse direito só pode ser concedido a humanos, a fotografia deveria ser considerada de domínio público, parecer favorável à Wikipedia, que pôde manter a imagem disponível em seu diretório virtual. O caso ainda será julgado oficialmente.

Essa disputa de direitos autorais, no entanto, ainda é baseada em uma visão tecnicista do ato fotográfico, conforme declarou o próprio fotógrafo ao jornal The Telegraf: "É tudo baseado em um tecnicismo. Eu possuo a foto, mas 
- Fig. 01: selfie do macaco

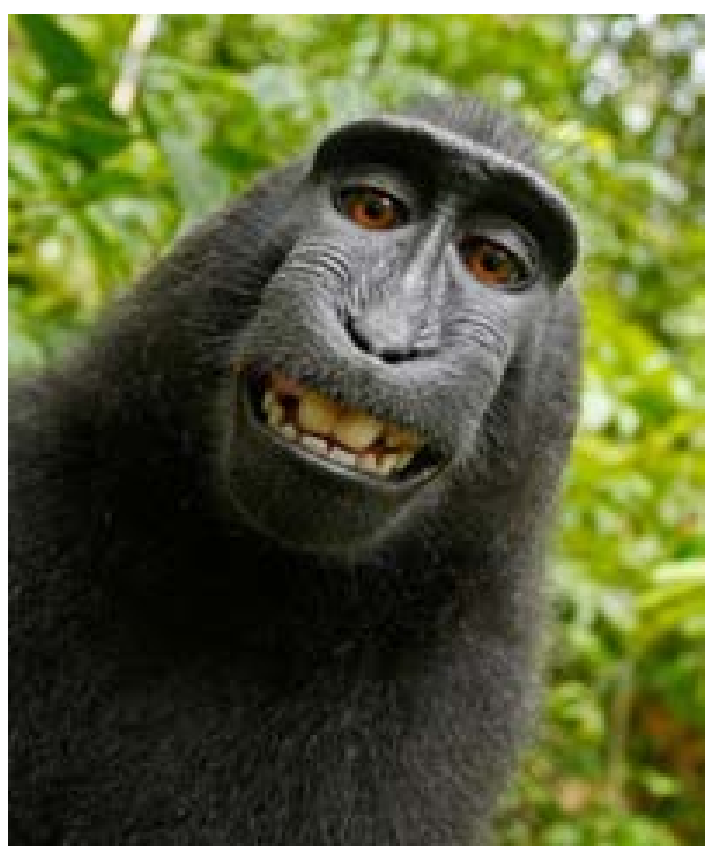

Disponível em: https://commons.wikimedia.org/wiki/File:Macaca nigra self-portrait.jpg

Acesso em: 6 fev. 2015

porque o macaco apertou o gatilho e tirou a foto, eles estão reivindicando que o macaco detém os direitos autorais"1.

A partir dessa decisão favorável ao macaco, é possível formular alguns questionamentos: ser fotógrafo é somente apertar o botão da câmera? Então se assim for, até um macaco pode ser fotógrafo? Ou seria a câmera a verdadeira autora da fotografia? Uma fotografia é o registro do real feito pela câmera e ao homem cabe a função de apertar o disparador?

Já se passaram 175 anos desde o anúncio público da fotografia, na reunião das Academias de Ciências e de Belas Artes, na França, em 1839. No entanto, esse pensamento ainda é bastante corrente, e parece ganhar força com a automação radical do clique, facilitada pela incorporação da câmera fotográfica aos dispositivos móveis.

A discussão aqui apresentada parte da crítica a essa automação do ato fotográfico. Uma "abordagem humanista", conforme define Soulages (2010, p.130), "isto é, relativa ao homem fotógrafo". A opção por esse enfoque humanista se soma à busca por uma compreensão de parte significativa da

1 Tradução livre do trecho: "It's all based on a technicality. I own the photo but because the monkey pressed the trigger and took the photo, they're claiming the monkey owns the copyright". 
produção fotográfica contemporânea, baseada no que será definido adiante como era da incompetência técnica. Afinal, quem fotografa hoje, o homem ou a câmera? Não poderia o "sorriso" do macaco ser tomado como um irônico deboche das incompreensões humanas sobre o fazer fotográfico?

A escolha por esse recorte crítico não despreza, contudo, as mudanças positivas possibilitadas pela automação do clique, como por exemplo, o impulso às renovações estéticas provocadas pela produção dos fotógrafos amadores. Apesar de considerar essa dialética da automação, a discussão apresentada a seguir será estruturada com base no que se perde quando o ato fotográfico é encarado apenas como uma competência técnica.

\section{Apontamentos sobre a automação fotográfica}

"No momento em que Daguerre logrou fixar imagens da câmera obscura, os técnicos substituíram os pintores", destaca Benjamim (2012, p. 103), no ensaio "A pequena história da fotografia", escrito em 1931. Ao falar sobre os anos iniciais da fotografia, o pensador deixa claro como o domínio da técnica era fundamental para os primeiros fotógrafos, muitos deles pintores que passaram a se dedicar a um novo ofício:

As coisas desenvolveram-se tão rapidamente que já por volta de 1840 a maioria dos pintores de miniaturas havia se transformado em fotógrafos profissionais, a princípio apenas de forma esporádica, mas já pouco depois exclusivamente. A experiência adquirida em seu ofício original foi-lhes muito útil, embora o alto nível do seu trabalho fotográfico se deva mais à sua formação artesanal que à sua formação artística (Benjamin, 2012, p. 103-104).

Ao enfocar esse domínio do artesanal, Benjamim enfatiza que a destreza dos fotógrafos pioneiros não se limitava ao ato fotográfico. Os profissionais eram responsáveis até mesmo pela produção das câmaras escuras e por preparar o suporte fotossensível em que a imagem seria fixada. Além disso, realizavam os procedimentos de revelação. Dominar todas as etapas do processo fotográfico fazia com que os primeiros fotógrafos tivessem uma destreza técnica bastante precisa.

Para Benjamin, esse período áureo da técnica durou apenas os primeiros anos. Logo, outros profissionais se apropriaram dos conhecimentos fotográficos²:

2 Cabe lembrar que a fotografia surgiu como uma técnica de domínio público, o que possibilitou sua rápida difusão. 
[...] finalmente os homens de negócio se instalaram profissionalmente como fotógrafos, e quando, mais tarde, o hábito do retoque, graças ao qual o mau pintor se vingou da fotografia, acabou por generalizarse, o gosto experimentou uma brusca decadência (Benjamin, 2012, p. 104).

Kossoy contrapõe-se à ideia de que a popularização da fotografia trouxe prejuízos. O autor considera que "seu consumo crescente e ininterrupto ensejou o gradativo aperfeiçoamento da técnica fotográfica" (Kossoy, 2012, p. 27). E justifica:

Essencialmenteartesanal, a princípio, esta se viu mais e mais sofisticada à medida que aquele consumo, que ocorria particularmente nos grandes centros europeus e nos Estados Unidos, justificou inversões significativas de capital em pesquisas e na produção de equipamentos e materiais fotossensíveis (Kossoy, 2012, p. 27-28).

Contrapor essas duas visões é essencial para compreender como o desenvolvimento da fotografia se situa numa zona de confrontos. É a partir dessas tensões que a técnica fotográfica passa de um estágio artesanal para ser cooptada pela indústria. "A enorme aceitação que a fotografia teve, notadamente a partir da década de 1860, propiciou o surgimento de verdadeiros impérios industriais e comerciais" (Kossoy, 2012, p. 28).

Um marco significativo desse processo de comercialização foi estabelecido por Eugène Disderi, que em 1854 patenteou a invenção do carte de visite ${ }^{3}$. Os retratos, que foram bastante lucrativos para os profissionais da época, atendiam aos anseios de visibilidade da burguesia, e em pouco tempo se tornaram tão acessíveis que até membros das classes baixas puderam se dar ao luxo de serem retratados. Fabris (2004) comenta que a popularização dos carte de visite marcou o ingresso da fotografia na fase da industrialização, considerado fator de decadência por Benjamin (2012).

A formação de um circuito comercial e social voltado à fotografia instituiu as bases para a industrialização propriamente dita. $O$ primeiro grande império industrial fotográfico foi idealizado pelo jovem bancário estadunidense George

3 O carte de visite consistia em um pequeno retrato, reproduzido em papel albuminado, colado sobre um cartão de papel rígido, geralmente assinado com a marca do estúdio fotográfico. $O$ processo inventado por Desderi possibilitou o registro de diversas imagens em uma única chapa, o que barateou o custo de produção das fotografias. Os carte de visite tornaram-se bastante populares no início da década de 1860 , o que possibilitou sua circulação social como objeto de troca entre familiares e nas rodas sociais. Os retratos eram preservados em álbuns, instituindo a prática de colecionar fotografias. 
Eastman, fundador da Eastman Dry Plate and Film Company-que posteriormente passaria a se chamar Kodak. Entre as principais contribuições do empresário para a fotografia, destacam-se a criação do filme flexível - feito de acetado de celulose -, patenteado em 1884, e a invenção da primeira câmera portátil: a Kodak $n^{\circ}$ 1, lançada em 1888.

Os inventos de Eastman foram responsáveis por uma ruptura na lógica de produção fotográfica. Pela primeira vez uma câmera poderia ser utilizada sem demandar nenhuma perícia técnica, conforme relata Rouillé (2009, p. 91):

[...] a fabricação de máquinas de pequeno formato, leves e flexíveis, e a produção industrial de produtos químicos de fácil utilização tornam a prática fotográfica acessível aos amadores, principalmente após o lançamento, em 1888, da famosa máquina Kodak, e de seu não menos famoso bordão "Aperte o botão, nós fazemos o resto".

A pequena câmera quadrada inventada por Eastman foi responsável por estabelecer um novo conceito para a fotografia: o automático. Não era mais necessário ter nenhum conhecimento de química, ótica ou composição. Bastava apenas apertar o disparador. O processo, que antes era dominado do começo ao fim pelo fotógrafo, tornou-se obscuro. A Kodak no 1 era uma pequena caixa de Pandora: misteriosa e dotada do fascinante poder de aprisionar em uma superfície bidimensional as imagens do mundo.

O empreendimento de Eastman deu tão certo que em pouco tempo a fotografia amadora se difundiu. A Kodak se consolidou no crescente mercado fotográfico, sempre com foco na facilidade do clique. Fotografar se tornou algo tão simples que até mesmo as crianças poderiam fazê-lo, conforme anunciava a propaganda da Kodak Brownie, lançada em 1900 e comercializada por um dólar. A popularização possibilitou que a fotografia fosse utilizada para novas funções, como o registro do cotidiano familiar ou a prática de instantâneos que subvertiam a lógica vigente da pose do retrato em estúdio.

A fotografia nasceu profissional.Depois se tornou industrial.O que possibilitou que fosse experimentada pelos amadores. Se por um lado a automação do clique liberou a fotografia para novas potencialidades funcionais e estéticas, por outro, favoreceu o reforço do imaginário fotográfico como um mero produto da técnica: "a fotografia estabeleceu um procedimento radicalmente novo: o do registro automático. A fotografia é, então, acusada de não omitir nada, de nada sacrificar [...]" (Rouillé, 2009, p. 41).

A incompreensão do processo formativo da imagem ajudou a sedimentar a ideia do recorte do real, ao qual a fotografia foi atrelada desde a sua gênese. 
Pensamento que se contrapõe às discussões mais atuais sobre a estética fotográfica, que buscam descolar da imagem o déficit de um realismo encenado.

\begin{abstract}
O realismo, que no início foi uma prática e uma doutrina necessárias, tornou-se imperialista, pois se confundiu e se quis confundir condição de possibilidade de um nascimento com condição de possibilidade de um funcionamento - em outras palavras, começo e essência (Soulages, 2010, p. 109).
\end{abstract}

Se nas discussões mais atuais a fotografia tenta se libertar do espectro do real -"o real é infotografável" (Soulages, 2010, p. 83) -, na prática esse imaginário ainda se encontra calcado em um alicerce muito sólido de incompreensões conceituais, fortalecido, principalmente, pela automação radical do clique. Para Rouillé (2009, p. 202), "as incompreensões mais fortes e as críticas mais intensas, a fotografia as deve à sua natureza de imagem tecnológica, ao fato de ser considerada como'uma imagem sem homem'".

Essa imagem desumanizada, cuja produção é atribuída meramente ao aparato técnico, parece ter ganhado ainda mais força com a radicalização da cultura digital. A fusão da câmera aos dispositivos móveis possibilitou que não só o clique fosse automático, mas todo o processo fotográfico tornou-se automatizado e ainda mais incompreendido.

Se na era analógica as fotos clicadas automaticamente ainda tinham que ser submetidas à perícia técnica dos laboratoristas - à exceção das polaroides -, agora, captação, processamento e até mesmo a difusão - propiciada pela conexão dos dispositivos com a internet - foram automatizados, o que instaurou o radicalismo da técnica.

\title{
A era da incompetência técnica
}

Muitos são os que foram alfabetizados, mas poucos são os que têm a competência para escrever um romance a altura de grandes nomes como Machado de Assis ou Honoré de Balzac. O mesmo se dá com a fotografia: qualquer um pode apertar o disparador, porém são raros os que têm o controle da câmera. A estes, é justo o título de fotógrafo. No entanto, quando a automação se faz imperativa, torna-se gradativamente mais raro encontrar quem domine $o$ equipamento com consciência e destreza.

Quando a técnica se torna a principal bandeira nas diversas instâncias sociais, é justamente a ausência dela que insere grande parte da fotografia em uma nova era: a da incompetência técnica. Nãoé mais o homem quem comanda o aparelho, mas o aparelho que parece impor suas vontades programadas. "Quem 
crê ser possuidor de aparelhos é, na realidade, possuído por ele. Doravante, nenhuma decisão humana funciona", assevera Flusser (2009).

Na era da incompetência técnica os homens devotam cada vez mais suas vontades às máquinas que, por terem escolhas limitadas, quase sempre acertam. O que as fazem parecer superiores à capacidade humana. Mas tal pensamento é ingênuo, visto que a vontade do homem e sua potência criativa são ilimitadas. Ou melhor, seriam, se seus anseios não passassem a ser substituídos pelas "vontades técnicas" dos aparelhos. "[...] o fotógrafo amador crê ser o fotografar gesto automático graças ao qual o mundo vai aparecendo" (Flusser, 2009, p. 55).

A incompetência técnica superestima a potencialidade dos novos aparelhos, e é responsável pela desconstrução da figura do fotógrafo, que gradativamente é destituído de seu papel social e profissional. Quando é imperativo que todos estejam diante da câmera, não é mais o fotógrafo quem vê, mas sim o aparelho - um velho pensamento atrelado à fotografia que encontra nova força na sociedade tecno-imagética que se consolida.

Para Benjamin (2012), na era da reprodutibilidade técnica - cujo principal propulsor foi a invenção da fotografia - a obra de arte perdeu sua aura, ou seja, a imagem deslocou a obra para outra lógica de espaço e tempo. A reprodução técnica foi responsável por provocar uma ruptura na experiência de fruição de um quadro, no espaço que foi destinado para sua contemplação, um museu, por exemplo.

A ideia da aura como experiência contemplativa fica clara no exemplo citado por Benjamim (2012, p.184): "Observar, em repouso, numa tarde de verão, uma cadeia de montanhas no horizonte, ou um galho, que projeta sua sombra sobre nós, significa respirar a aura dessas montanhas, desse galho". A fotografia, enquanto representação técnica, rompe com essa lógica da experiência, ou seja, a obra de arte - e as demais ações humanas - perdem sua aura.

Se na era da reprodutibilidade técnica a obra de arte perdeu sua aura, na era da incompetência técnica o homem perde o domínio da câmera. "Fotografa automaticamente", destaca Flusser (2009, p. 54, grifo do autor). A vontade dos indivíduos fica subjugada à competência programada dos aparelhos. Já não é o homem que opera vontade sobre eles: "É precisamente isso que o termo 'automação' significa: processo de acidentes programados do qual a intenção humana foi eliminada, para se refugiar no programa produtor dos acidentes" (Flusser, 2008, p. 33).

$\mathrm{Na}$ era da incompetência técnica, "a fotografia está sendo manipulada como um ritual de magia" (Flusser, 2009, p. 56). À medida que o ato fotográfico se tornou radicalmente automático, a compreensão do homem sobre essa ação 
ficou cada vez mais indecifrável. E isso tem uma consequência direta: “[...] tudo o que não deciframos nos devora", alerta Baitello Junior (2005, p. 33). Em frente às câmeras, o homem está diante da Esfinge. Incapaz de decifrar o código da "Caixa Preta" (Flusser, 2009), passa a ser devorado pelos seus produtos.

O homem, ao invés de se servir das imagens em função do mundo, passa a viver em função das imagens. Não mais decifra as cenas da imagem como significados do mundo, mas o próprio mundo vai sendo vivenciado como conjunto de cenas. Tal inversão da função das imagens é idolatria (Flusser, 2009, p. 9).

Essa formatação da vida em função das imagens parece seestabelecer como uma das principais marcas deste tempo, em que Eco e Narciso se estabeleceram como arquétipos. Eco como referencial da cópia, mera reprodução das últimas sílabas. Narciso como representante da paixão ao próprio reflexo, sedado, indiferente ao que o cerca. Não é por acaso que Narciso e narcose nascem do mesmo radical: fotografar tornou-se um vício, conforme prenunciou Flusser (2009, p. 54, grifo do autor):

O aparelho é brinquedo sedento por fazer sempre mais fotografias.
Exige de seu possuidor (que por ele está possesso) que aperte
constantemente o gatilho. Aparelho-arma. Fotografar pode virar
mania, o que evoca uso de drogas. Na curva desse jogo maníaco,
pode surgir um ponto no qual o homem-desprovido-de-aparelho
se sente cego. Não sabe mais olhar, a não ser através do aparelho.
[...] Está dentro do aparelho, engolido por sua gula. Passa a ser o
prolongamento automático do seu gatilho.

Em tempos de incompetência técnica, as imagens tornam-se limitadas. Ecos que reverberam cada vez com menos força. Não são imagens da imaginação, mas clichês, que perdem em profundidade, em avesso. Miradas de aparelhos programados e programadores. Afetadas em sua capacidade de afetar. Não é exagero afirmar que as imagens entraram em colapso: "A crise da visibilidade não é uma crise das imagens, mas uma rarefação de sua capacidade de apelo. Quando o apelo entra em crise, são necessárias mais e mais imagens para se alcançar os mesmos efeitos. O que se tem, então é uma descontrolada reprodutibilidade" (Baitello Junior, 2005).

Para tentar compensar a incapacidade técnica da tomada fotográfica, ajustes automáticos de softwares ou filtros tornam-se obrigatórios. Uma incompetência cumulativa, que acaba por instituir imagens programadas pelos aparelhos, cuja "vontade" programática se sobrepõe às intenções expressivas 
e de construção mnemônica. "Quem contemplar álbum de fotógrafo amador, estará vendo a memória de um aparelho, não de um homem", observa Flusser (2009, p. 54).

É a reprodutibilidade técnica elevada ao máximo: uma reprodutibilidade da técnica. Depois da perda da aura, há uma gradativa perda do poder enunciativo, da capacidade comunicante e complexa das imagens. Mas, apesar de estarem acometidas nessas competências, tais fotografias nunca deixam de dizer algo, ao contrário, parecem expor as próprias bases conceituais das imagens técnicas. No entanto, ao invés de serem tomadas como artefatos de elucidação, tornamse incógnitas indecifráveis, enigmas da Esfinge.

\section{Fotografia: de crime passional a morte em série}

Muitos são os autores que fazem alusão à câmera como uma arma. As mais diversas armas: de revólveres a lâminas cortantes. Para Sontag (2004, p. 24), "uma câmera é vendida como uma arma predatória - o mais automatizada possível, pronta para disparar". Dubois (2010, p. 178), compara o fotógrafo a um esquartejador: "sempre recorta, separa, inicia o visível. Cada objetivo, cada tomada é inelutavelmente uma machadada [...]". Se o ato fotográfico é uma machadada, é porque a câmera é tomada por machado, a golpear o tempo.

Flusser (2009, p. 29) considera que o portador da câmera-arma é um caçador: "Quem observa os movimentos de um fotógrafo munido de um aparelho (ou de um aparelho munido de fotógrafo) estará observando movimento de caça". Se a câmera é tomada como um artefato de artilharia, fotografar alude a um crime: "Assim como a câmera é uma sublimação da arma, fotografar alguém é um assassinato sublimado - um assassinato brando, adequado a uma época triste e assustada" (Sontag, 2004, p. 25).

Não foi por acaso que Benjamim (2012, p. 115) comparou as fotografias de Atget a cenas delituosas: "Mas não é cada recanto de nossas cidades o local de um crime? Não é cada passante um criminoso? Não deve o fotógrafo, sucessor de áugures e arúspices, descobrir a culpa em suas imagens e denunciar o culpado?" O que o autor parece não ter se dado conta é que o próprio fotógrafo é o responsável pelo crime, cuja fotografia é a prova que pretende se mostrar incontestável.

“Fotografar, como suicidar-se, é deter a vida, gravá-la de forma grave, fixála na morte e na arte, é assinar com sangue sua obra de arte e sua vida, é tentar romper com a finitude e o trágico afirmando-os", defende Soulages (2010, p. 210). E complementa: "É preciso não ter piedade para fotografar" (Soulages, 2010, p. 211). Para os fotógrafos da era da técnica, fotografar era um crime 
passional: a câmera-arma golpeava o objeto que lhe havia seduzido os olhos. A paixão envolvida no ato demonstrava que a intenção humana direcionava o aparato técnico.

$\mathrm{Na}$ era da incompetência técnica, fotografar não é um ato apaixonado. É uma relação desumanizada, que evoca a lógica fria do serial killer. Mera impressão de um aparelho disparado por um dedo humano destituído de vontade afetiva, autômato. Eis um dos motivos pelo qual as fotografias gestadas pela incompetência técnica parecem não ter força: superfícies que não se desdobram em profundidades.

Quando a fotografia deixa de ser um crime passional e passa a ser assassinato em série, não há mais uma busca pelas ficções da realidade interior dos fotógrafos. Os registros da incompetência técnica são sempre remissivos a outras imagens, ou seja, tendem a se descolar do imaginário para aderir ao já imaginado. Nesse ponto, a fotografia perde sua força enquanto memória afetiva, estética ou histórica e ganha força como memória imagética. A memória é a profundidade da imagem. Não é à toa que as imagens tiveram sua capacidade de apelo reduzida. São menos memoráveis, ou seja, afetada em sua capacidade de suscitar recordações.

Mas essa própria mudança no status do crime fotográfico não é por acaso. Está inserida na crença irracional nas máquinas e na dúvida no irremediavelmente humano. Um radicalismo do pensamento positivista, do qual a fotografia é uma das filhas mais estimadas. A descrença no real faz com que as ficções da técnica sejam tomadas como mais verdadeiras que a própria realidade.

\footnotetext{
Trata-se da alienação do homem em relação a seus próprios instrumentos. O homem se esquece do motivo pelo qual imagens são produzidas: servirem de instrumentos para orientá-los no mundo. Imaginação torna-se alucinação e o homem passa a ser incapaz de reconstruir as dimensões abstraídas (Flusser, 2009, p. 9, grifo do autor).
}

A imagem automática se torna mais "crível", pois a intencionalidade humana, falível, é sempre posta em questionamento. O grande equívoco é que a câmera sempre é a programação de uma intenção do programador, que nunca é isenta. A descrença no homem leva à crença ingênua na máquina. Mas que seria uma máquina senão uma construção humana? 


\section{Em defesa da crítica}

A era da incompetência técnica tem provocado mudanças radicais no ato fotográfico e no modo como a fotografia se insere na sociedade. A própria câmera passou por transformações. Deixou de ser um aparato único para se tornar uma pequena lente acoplada aos dispositivos portáteis. Isso trouxe uma modificação positiva, possibilitou que novas cenas fossem registradas. Em contrapartida, fotografar tornou-se um ato banal, ubíquo e radicalmente automático. Mas será que o homem sabe lidar bem com o excesso de imagens? As facilidades são mesmo positivas? E mais: quem exerce sua vontade, o homem ou a câmera?

Em 2007, a Sony lançou as câmeras compactas da série $T$, que tinham como principal diferencial o recurso smile shutter. Selecionada essa opção, o aparelho disparava automaticamente quando o sistema de reconhecimento facial detection face - identificava um sorriso. $\mathrm{O}$ "passarinho" tornou-se obsoleto. Por meio dessa função - que foi aprimorada pela Sony nos lançamentos posteriores -, a própria câmera escolhia o melhor sorriso e registrava automaticamente. O recurso foi vendido e publicizado com uma justificativa: registrar sorrisos espontâneos. Mas poderia um aparelho determinar o que é espontâneo? Ou melhor, qual a espontaneidade de um sorriso ante uma câmera?

As novas formatações dos aparelhos e gadgets levam a crer que a vontade humana se tornará cada vez mais acessória. Até mesmo o enquadramento pode deixar de ser uma escolha de quem fotografa para ser definida pelo aparelho. Ao menos é a isso que se propõe o aplicativo Camera 51, disponível gratuitamente para plataforma Android. O programa "convida-o a tirar fotos profissionais", para isso "detecta e analisa rostos, cenas, objetos e linhas e orienta-o para o enquadramento perfeito em cada clique". Basta que o usuário siga as orientações do software e arraste o smartphone para o enquadramento escolhido pelo aplicativo.

Não seria isso aprisionar a fotografia à lógica ultrapassada - mas ainda bastante recorrente - da fotografia como um mero registro técnico? Não seria destituir a imagem fotográfica de seu poder comunicativo e imaginativo? Não seria submeter a subjetividade do indivíduo à lógica automatizante de um aparelho? A uma conformação ocultada atrás do fascínio tecnológico? A quem serve aprisionar a fotografia ao déficit do real? À indústria? À conformação social ante as imagens? Ao sistema idólatra das imagens técnicas?

Flusser (2008, p. 72-73) traça um apontamento plausível que se encaixa como resposta provisória para essas inquietações:"as imagenstécnicas significam programas. São projeções que partem de programas e visam programar seus 
receptores. As cenas mostradas pelas imagens técnicas são métodos de como programar a sociedade".

Apesar de parecer uma teoria conspiracionista, o que Flusser deixa implícito em seu pensamento é que os indivíduos são diretamente afetados programados - pelas imagens que produzem:"as imagens alimentam os homens para serem por eles realimentadas e para engordarem sempre mais durante o processo" (Flusser, 2008, p. 77). O que remete ao conceito de iconofagia, do crítico da comunicação Baitello Junior (2005, p. 97): "Alimentar-se de imagens significa alimentar imagens, conferindo-lhes substância, emprestando-lhes os corpos. Significa estar dentro delas e transformar-se em personagem [...]. Ao contrário de uma apropriação, trata-se aqui de uma expropriação de si mesmo".

No entanto, apesar de esse processo ser bastante incisivo, cabe ressaltar que as demandas dos aparelhos não são impositivas, mas sim sugestivas. "Os aparelhos não são deuses ou super-homens, mas autômatos infrahumanamente cretinos" (Flusser, 2008, p. 107). Por mais que a vontade humana seja enfraquecida ante a automação, é preciso frisar que "há sempre um sujeito que fotografa, mesmo que a foto seja feita automaticamente e até de maneira aleatória, pois um sujeito sempre preside a tomada da foto" (Soulages, 2010, p. 126).

É nesse ponto que a crítica se faz necessária. "Enquanto não existir crítica fotográfica que revele essa ambiguidade do código fotográfico, a intenção do aparelho prevalecerá sobre a intenção humana" (Flusser, 2009, p. 43). Sem a crítica, as imagens técnicas continuarão a se colocar como anteparos, a ofuscar as coisas do mundo.

\footnotetext{
A tarefa da crítica de imagens técnicas é pois precisamente a de des-ocultar os programas por detrás das imagens. A luta entre os programas mostra a intenção produtora humana. Se não conseguimos aquele deciframento, as imagens técnicas se tornarão opacas e darão origem a nova idolatria, a idolatria mais densa que a das imagens tradicionais antes da invenção da escrita (Flusser, 2008, p. 36).
}

E em que consiste a crítica?"O dever de toda crítica dos aparelhos é mostrar a cretinice infra-humana dos aparelhos", declara Flusser (2009, p. 69). Ou seja, é necessário compreender que a função dos aparelhos é servir à vontade do homem, e não o contrário. Nesse sentido, a compreensão crítica nada mais é do que uma tomada de consciência emancipadora: "Os programas não devem mais correr dos aparelhos rumo ao homem, mas do homem rumo ao aparelho. 
Não homens, mas aparelhos devem ser programados, e o devem ser por decisão humana em prol da liberdade humana" (Flusser, 2008, p. 109, grifo do autor).

Essa consciência, no entanto, vai de encontro à lógica vigente, em que como já foi discutido anteriormente - as imagens são as últimas sílabas repetidas por Eco e espelhos de Narciso. Emancipar-se da ordem automática dos aparelhos é libertar as próprias imagens. É restituir-lhes a capacidade técnica e o poder enunciativo, para que voltem a ser mapas que situam o homem no mundo e não mais biombos que servem como anteparos da experiência (Flusser, 2009, p. 9).

Revelar a cretinice dos aparelhos, bem como suas intencionalidades, é reconstituir a crença na capacidade inventiva do homem. É reestabelecer o imaginário como centro criador, e não mais devotar essa capacidade aos aparatos tecnológicos. É encarar a câmera como o meio pelo qual se diz, se constrói ou se fabula algo. É decifrar o código da "Caixa Preta", para que ela seja um materializador de subjetividades, e não a responsável por espalhar os males de Pandora.

\section{O último clique}

Antes, as fotografias serviam para olhar além. Trazer para próximo dos olhos paisagens distantes e entes queridos que suscitavam saudades. Na era da incompetência técnica, a fotografia tornou-se a distância de um braço. Espelhos que refletem Narciso. O homem se vê privado até do próprio olhar, é a câmera que mira, escolhe o ângulo. A quem fotografa cabe apenas apertar o botão. Ou nem isso. De homem-fotógrafo, passou-se a homem-personagem, a encenar poses em frente ao aparelho, e agora parece tornar-se um homem-tripé, cuja única função é servir de suporte para a "vontade" automática - e automatizante - da câmera.

Nesse sentido, que difere os atuais retratos nas redes sociais daqueles feitos pelos macacos da ilha Sulawesi? Não seriam registros da mesma automação? Não seriam produtos da mesma incompreensão do clique? Não seriam registros da câmera e não da vontade humana? Não seriam as caretas dos macacos análogas às duck faces dos selfies? Essas são apenas questões retóricas. Não têm como objetivo encontrar respostas, mas provocar reflexões, suscitar o pensamento crítico, talvez único meio que nos diferencie dos macacos, até porque eles até já fotografam melhor do que muitos.

Na era da incompetência técnica ainda se pode chamar fotografia? Se a resposta for sim, é preciso libertar a imagem do seu papel comunicativo, e considerá-la uma mera técnica de reprodução. O que, pelas próprias discussões dominantes da história da fotografia, se mostra como um equívoco. Se a defesa 
for do não, seria necessário pensar um conceito novo para dar conta dessa produção, mas isso também não se mostra muito consistente, visto que a técnica ainda é fotográfica. Isso estabelece uma questão dialética, ou seja, essencialmente fotográfica.

No contexto desta discussão, considera-se mais pertinente compreender que na era da incompetência técnica a fotografia subsiste afetada em sua complexidade. Um vestígio de um ideal pré-fixado do que seria fotografia. Essa afetação, num primeiro momento, não se apresenta como prenúncio de uma aniquilação, mas como possibilidade de reconstrução: intelectual, enunciativa, documental, mnemônica e artística. A fotografia se aproxima de seus limites, expondo assim suas bases conceituais. Mas, como vestígio, a fotografia apresenta uma grande potencialidade para renascer, o que evoca o mito da Fênix. Ao menos por enquanto.

\section{Referências}

BAITELLO JUNIOR, Norval. A era da iconofagia. São Paulo: Hacker Editores, 2005.

BENJAMIN, Walter. Magia e técnica, arte e política: ensaios sobre literatura e história da cultura. São Paulo: Brasiliense, 2012.

CAMERA51. Camera51 a smarter câmera. Disponível em: https://play.google.com/ store/apps/details?id=com.camera51.android. Acesso em: 23 de fevereiro de 2005.

CATERS NEWS AGENCY. Cheeky Monkey Pictures. http://www.catersnews.com/ stories/animals/cheeky-monkey-pictures/. Acesso em 6 de fevereiro de 2015.

DUBOIS, Philippe. $\mathbf{O}$ ato fotográfico. 13. ed. Campinas: Papirus, 2010.

FABRIS, Annateresa. Identidades virtuais: uma leitura do retrato fotográfico. Belo Horizonte: Ed. UFMG, 2004.

FLUSSER, Vilém. $\mathbf{O}$ universo das imagens técnicas: elogio da superficialidade. São Paulo: Annablume, 2008.

. Filosofia da caixa preta: ensaios para uma futura filosofia da fotografia. Rio de Janeiro: Relume Dumará, 2009.

KOSSOY, Boris. Fotografia e história. 4. ed. São Paulo: Ateliê Editorial, 2012.

ROUILLÉ, André. Fotografia: entre documento e arte contemporânea. São Paulo: Senac, 2009. 
SLATER, David J. Selfie do macaco. DJS Photography. Disponível em: http://www. djsphotography.co.uk/. Acesso em 06 de fevereiro de 2015;

SONTAG, Susan. Sobre fotografia. São Paulo: Companhia das Letras, 2004.

SOULAGES, François. Estética da fotografia: perda e permanência. São Paulo: Senac, 2010.

THE TELEGRAPH, David Slater's monkey selfie photoshoot - the unseen pictures. Disponível em http://www.telegraph.co.uk/news/picturegalleries/ earth/11021255/David-Slaters-monkey-selfie-photosoot-the-unseen-pictures. html?frame=3000639. Acesso em: 6 de fevereiro de 2015.

Recebido em 30/4/2015

Aceito em 19/5/2015

Endereço do autor:

Maria Luísa Hoffmann <maluhoffmann@yahoo.com>

Rua Belo Horizonte, 1302 Apt. 9

CEP: 86020-061, Londrina - PR

Michel de Oliveiras <michel.os@hotmail.com.br>

michel.os@hotmail.com.br

Rua Luiz Lerco, 355

Torre II, apt. 1502.

CEP: 86047-610, Londrina - PR 
